\title{
Simulation Analysis of Impact of Smart Grid and Renewable Energy on GHG Emission
}

\author{
Yucheng $\mathrm{Zhu}^{1,2}$, Keyu Lu ${ }^{3}$, Zhaoling $\mathrm{Li}^{1}$, Noriko Nozaki ${ }^{1} \&$ Takeshi Mizunoya ${ }^{1}$ \\ ${ }^{1}$ Graduate School of Life and Environmental Sciences, University of Tsukuba, Tsukuba, Ibaraki, 3050005, Japan \\ ${ }^{2}$ Jiaxing University, Zhejiang, 314001, China \\ ${ }^{3}$ Chinese Society for Urban Studies, Beijing, 100835, China \\ Correspondence: Keyu Lu, Chinese Society for Urban Studies, Beijing, 100835, China. Tel: 86-183-1011-2528. \\ E-mail: lukeyu@chinasus.org
}

Received: August 2, 2017

Accepted: August 22, $2017 \quad$ Online Published: September 29, 2017

doi:10.5539/jsd.v10n5p181

URL: https://doi.org/10.5539/jsd.v10n5p181

\begin{abstract}
China once again promises to manage energy consumption and peak $\mathrm{CO}_{2}$ emission around 2030 in Paris Agreement in 2016 that expresses her ambition of mitigating emission. Using renewable energy to optimize energy structure is recognized as effective countermeasure to reduce GHG emission. Additionally, it is inevitable that improving energy efficiency is still core issue in energy usage. Smart Grid (SG) and renewable energy are collectively introduced in this research. Power supply and demand model is constructed to analyze the effect of SG and renewable energy on energy usage. Input-Output (I-O) simulation model is applied to make dynamic analysis based on extended I-O framework. Comprehensive model is constructed to evaluate the impact of SG and renewable energy on economic growth, energy usage and environmental improvement under different emission limitation. The proper policies covering carbon tax and subsidy are proposed to mitigate GHG emission, improve energy usage and optimize economic structure. Trade-off among economic growth, energy conversation and environmental improvement is realized in the study area.
\end{abstract}

Keywords: simulation analysis, smart grid, renewable energy, GHG emission, input-output

\section{Introduction}

Greenhouse gas (GHG) emission has cumulatively increase over the last decade in despite of a growing number of mitigation policies were implemented. Global emissions of $\mathrm{CO}_{2}$ from fossil fuel combustion and cement production have continued to grow by $2.5 \%$ per year on average over the past decade (P. Friedlingstein et al, 2014). For a $66 \%$ probability of staying below a temperature threshold of $2{ }^{\circ} \mathrm{C}, \mathrm{CO}_{2}$ emissions would need to be kept below 3,670 $\mathrm{GtCO}_{2}$ if accounting for forcing from $\mathrm{CO}_{2}$ only according to the Fifth Assessment Report of the Intergovernmental Panel on Climate Change (IPCC, 2013). Besides, $\mathrm{CO}_{2}$ emission caused by energy consumption will continuously increase to $360 \mathrm{Gt}$ by 2040 even though it will be mitigated from 6.5 to $1.6 \mathrm{Gt}$ each year (IEA 2016). Once again, China promises to manage energy consumption and peak $\mathrm{CO}_{2}$ emission around 2030 in Paris Agreement in 2016 that expresses her ambition of mitigating emission. As one of most developed region in China, energy consumption of Zhejiang province measured by coal equivalent increase by $63 \%$ in 2005-2015 (ZPBS, 2016) and thermal power accounts for $79.8 \%$ of total power supply (CEC, 2013), which exposes enormous amounts of GHG is still being emitted along with economy averagely grows at $10 \%$ during the decade (ZPBS, 2016).

Using renewable energy to vary energy structure is recognized as effective countermeasure to mitigate GHG emission. Zakaria Zoundi (2017) assess the short and long run impacts of renewable energy on $\mathrm{CO}_{2}$ emissions by virtue of combination a panel co-integration analysis with a set of robustness tests, as well as the Kuznets Environmental Curve (EKC) hypothesis for twenty five selected African countries. The conclusion reveals renewable energy, with a negative effect on $\mathrm{CO}_{2}$ emissions, remains an efficient substitute for the conventional fossil-fuelled energy. Eyup Dogan and Fahri Seker (2016) empirically analyze the impacts of renewable and nonrenewable energy, real income and trade openness on $\mathrm{CO}_{2}$ emissions in the $\mathrm{EKC}$ model for the European Union over the period 1980-2012 by employing panel estimation techniques robust to cross-sectional dependence. On the basis of testing EKC using renewable energy and non-renewable energy consumption as 
explanatory variables, the impact of renewable energy and nonrenewable energy consumption on $\mathrm{CO}_{2}$ emission is modeled and proved by Danish et al. (2017). Moreover, improving renewable energy efficiency is researched as well. F.R. Pazheri (2015) model a clean and efficient hybrid power system scheduling consist of fossil fuels and renewable energy in presence of energy storage facilities and demonstrates it is available during peak demand periods. The performance of hybrid PV-Wind-Diesel-Battery configuration is optimized by means of Hybrid Optimization Model for Electric Renewable (HOMER) software which uncovers renewable energy system (PV-Wind) is able to supply about $70 \%$ of the demand, and $69 \%$ of the fossil fuel can be saved when using the proposed hybrid configuration instead of the diesel generators (Baghdadi 2015). In addition, usage of renewable energy such as solar energy, wind energy, is modeled and evaluated from the point of policy and technology (S. Avril et al 2012; Martins, F 2017; Petrillo et al. 2016; Bernal et al.2017; Sun et al. 2015)

Especially, researchers comprehensively assess GHG emission mitigation and economic growth embedded by renewable energy. Faisal Mehmood Mirza and Afra Kanwal (2017) explore the presence of dynamic causality between economic growth, energy consumption and $\mathrm{CO}_{2}$ emissions, and suggest government should focus on building resources for ensuring adequate energy supplies in the economy by gradually increasing the share of renewable energy resources in the overall energy mix. Fethi Amri (2017) analyzes economic growth-energy consumption nexus in Algeria between 1980 and 2012 using co-integration tests and proposes policy makers in Algeria should enhance the renewable energy share together with controlling the non-renewable one. Lu et al. (2016) introduce carbon tax and subsidy for hybrid vehicle, electric vehicle and renewable power, and comprehensively evaluate the effect of GHG emission and economic growth by simulation based on extended input-output (I-O) model. Song et al. (2015) construct dynamic simulation model with I-O analysis to assess the impact of renewable energy and industrial restructuring on economic development, energy consumption and GHG emission.

The Smart Grid (SG) offers an answer to the shift to more sustainable technologies such as distributed generation and micro-grids. It allows renewable energy resources to be safely plugged into the grid to supplement the power supply (Tuballa \& Abundo, 2016). Hossain et al. (2016) review the concept and availability of renewable energy and the role of SG in renewable energy. The conclusion shows SG has good potential to be applied in renewable energies, and it should be updated for maintaining multifarious sources of electricity allocated in space and find ways of managing these by more complicated systems. Conti and Rizzo (2014) propose SG reduces the negative impact of distributed generators' (DGs) high penetration. They present a new probability of adequacy formulation, which encompass four types of power correlation of loads and generators, and assess the ability of local DGs to meet the load of a potential distribution island. SG is also considered as the ultimate solution to challenges that emerge from the increasing power demands. Four power-demand scheduling scenarios are analyzed by Vardakas et al. (2015) in order to reduce the peak demand in a SG infrastructure. The conclusion indicates a significant peak demand reduction can be achieved by scheduling the appliances' operation. Yu et al. (2015) establish new model to comparatively evaluate technical and allocative efficiency of SG in fifteen regions of China based on Stochastic Frontier Model and Data Envelopment Analysis.

Additionally, SG are analyzed from the point of feature, prospects and challenges when it is being applied in many countries. The US imagines in future electric system, electricity and information flow together in real time, near-zero economic losses from outages and power quality disturbances, and all supported by a new energy infrastructure built on superconductivity, distributed intelligence and resources, clean power, and the hydrogen economy (Grid 2030). The EU is regarded as world leadership in SG technology (Iqtiyanillham et al. 2017), and SG's key challenges in EU are the system integration of various disciplines, overcoming of regulatory barriers, technology maturity, and consumer engagement. The success of future grids requires political and regulatory support and the reconstruction of energy generation, market and usage. The German energy storage market is analyzed and the operation strategies of the two most profitable applications, self-consumption maximization and primary frequency control are described by Rescha et al. (2017). Haidar et al. (2015) review SG system in some states in Australia, and offer some examples on SG at distribution level dealing with interconnection of distributed generation and active distribution management.

Nevertheless, applying renewable energy to mitigate GHG emission implies that power is completely stable when renewable energy is introduced into power grid. In practice, supply of solar power and wind power fluctuates so that the power grid is in the face of shock in real time. On the other hand, the relationship between SG and renewable energy and efficiency of SG are analyzed in the reviews without regard to their influence on regional economy. SG and renewable energy have an effect on regional economic growth, energy supply and demand and GHG emission. Up to now, these effect has not been overall analyzed and evaluated. This research comprehensively evaluates the impact of introducing SG and renewable energy on GHG emission in Zhejiang 
province of China, and maximizes the gross regional product (GRP) growth under the GHG emission limitation. On this basis, optimizing policies are proposed to improve economic and energy structure, and realize economic and environmental trade-off. In the research, power supply and demand model is constructed to evaluate the impact of SG introduction. Comprehensive model is constructed to simultaneously analyze the impact of SG and renewable energy on GHG emission, energy supply and demand and GRP growth.

The remainder of this paper is organized as follows: methodology including assumption, framework, sectoral category, scenarios setting and data acquisition, will be explained in Section 2. Section 3 will present the comprehensive model to simulate the environmental change, energy improvement and economic growth. Major results will be discussed in Section 4. In the end, Section 5 will come to conclusion and propose some policies.

\section{Methodology}

\subsection{Modeling Assumption}

Based on general equilibrium theory, I-O model is applied to macro-economic analysis which uncovers interrelationships of production, reproduction and consumption among socioeconomic sectors (Leontief, 1936). It is also widely used to comprehensively analyze environmental impact, energy consumption and economic growth (Nijkamp, 1977; Lu et al., 2016; Song et al., 2015). Some basic assumption is implied in the I-O model. Total input is equivalent to total output in the environmental-economic system, and supply and demand of product, service and energy balance at level of equilibrium output as well. All variables in the model are identified as linearity in order to quantitatively analyze the interaction of socio-economy, energy and environment regardless of their random disturbance in complex system. The coefficients, such as input-output coefficient, energy supply and demand coefficient and GHG emission coefficient, are constant without affected by technological advance, variation of supply and demand and economic fluctuation. Besides, Direct and indirect tax rate is also constant as the government's tax policy is coherent during a specific period.

\subsection{Modeling Framework}

Modeling framework of this research is illustrated in Figure 1. The whole socio-economic system is divided into six entities, which are comprised of usual industry, conventional energy industry, SG, renewable power industry, government sector and private sector. Usual industry provides energy sectors, smart gird, government and private with products and service. All the energy is supplied by conventional energy industry and renewable power industry to usual industry, government and private via SG. SG and renewable power industry are collectively subsidized by government. Carbon tax, indirect tax and direct tax are imposed from industrial sectors and private sector, meanwhile government saving and private saving is invested to industrial sectors and other regions. Private obtains income from industrial sectors and pays the direct tax to government. Products, service and energy are traded with other regions which is regarded as regional import and export. GHG emits from industrial sectors, government consumption and private consumption.

\subsection{Sectoral Category}

Categories of industrial sectors are shown in table 1. Usual industry, which provides products and service, is composed of eleven industries that are coded by u1-u11. Conventional energy industry consists of coal, oil and fuel gas that are coded by $\mathrm{c} 1-\mathrm{c} 3$. Electricity industry comprises SG industry and five power generation industries which are coded by e1-e6. In addition, electricity stability is defined as three categories in table 2. Static stability, which is coded by B1, is defined that electricity is absolutely stable without any outage, and it includes u2, u7 and $\mathrm{u} 8$ in usual industry. Dynamic stability I that is coded by B2, means outrage is acceptable but it recovers in 10-20 seconds, which contains $\mathrm{u} 3, \mathrm{u} 4$, u5 and $\mathrm{u} 6$ in usual industry and private sector. The definition of dynamic stability II is that outrage is not acceptable but voltage is unstable within a range of plus or minus $10 \%$. It is coded by B3, and covers $\mathrm{u} 1, \mathrm{u} 9, \mathrm{u} 10$ and $\mathrm{u} 11$ in usual industry. 
Table 1 . Sectoral category

\begin{tabular}{lll}
\hline & Code & Category \\
\hline Usual industry & $\mathrm{u} 1$ & Farming \\
$\mathrm{u} 2$ & Light industry \\
$\mathrm{u} 3$ & Chemical \\
$\mathrm{u} 4$ & Non-metal \\
$\mathrm{u} 5$ & Metal \\
$\mathrm{u} 6$ & General equipment manufacturing \\
$\mathrm{u} 7$ & Electric equipment and machinery \\
$\mathrm{u} 8$ & Electronic equipment manufacturing \\
$\mathrm{u} 9$ & Construction \\
$\mathrm{u} 10$ & Transportation \\
$\mathrm{u} 11$ & Service \& others \\
$\mathrm{c} 1$ & Coal \\
$\mathrm{c} 2$ & Oil and petroleum \\
$\mathrm{c} 3$ & Fuel gas \\
\hline Conventional energy industry & Smart grid \\
e2 & Thermal power \\
e3 & Nuclear power \\
electricity industry & Hydropower \\
& e5 & Solar power \\
$\mathrm{e} 6$ & Wind power \\
\hline
\end{tabular}

Table 2 . Electricity stability category

\begin{tabular}{llll}
\hline Code & Stability & Sectoral Code & Sectoral Category \\
\hline B1 & Static stability & $\mathrm{u} 2$ & Light industry \\
& & $\mathrm{u} 7$ & Electric equipment and machinery \\
& & $\mathrm{u} 8$ & Electronic equipment manufacturing \\
\hline B2 & Dynamic stability I & $\mathrm{u} 3$ & Chemical \\
& & $\mathrm{u} 4$ & Non-metal \\
& & $\mathrm{u} 5$ & Metal \\
& & $\mathrm{u} 6$ & General equipment manufacturing \\
& & $\mathrm{u} 1$ & Private sector \\
\hline B3 & Dynamic stability II & $\mathrm{u} 9$ & Farming \\
& & $\mathrm{u} 10$ & Construction \\
& & $\mathrm{u} 11$ & Transportation \\
& & Service \& others \\
\hline
\end{tabular}




\subsection{Scenarios Setting}

Differentiated scenarios are set for comparative analysis in the table 3. S0 is set as business as usual (BAU) to predict the actual economic growth, energy supply and demand and GHG emission. Carbon tax is imposed on usual industries, conventional energy industries and thermal power industry in order to constraint GHG emission from these industries. SG and renewable energy are subsidized so that they can be developed and utilized by policy support. Emission targets can be achieved along with industrial emission constraint and change of power supply structure. Therefore, emission reduction targets are set $10 \%$ in S1, 20\% in S2 and 30\% respectively to analyze economic growth, energy supply and demand and GHG emission by comparison.

Table 3. Scenarios setting

\begin{tabular}{lllll}
\hline & Carbon tax & Subsidy for renewable power & Subsidy for smart grid & Carbon emission reduction (\%) \\
\hline S0 & $\times$ & $\times$ & $\times$ & $\times$ \\
S1 & $\circ$ & $\circ$ & $\circ$ & 10 \\
S2 & $\circ$ & $\circ$ & $\circ$ & 20 \\
S3 & $\circ$ & $\circ$ & $\circ$ & 30 \\
\hline
\end{tabular}

Note. "०" indicates policy is implemented, " $\times$ "indicates policy is not implemented.

\subsection{Data Acquisition}

The software LINGO is applied in this research to calculate the comprehensive model by computer simulation and in search of optimized solution, which reveals the distinct policy effects on economy growth, energy usage and environment improvement. The extend I-O table embracing SG and renewable energy is acquired based on Zhejiang province I-O table 2012 (ZPBS, 2015). Input coefficient of product and service, input coefficients of capital stock, income rate, indirect tax rate, capital output ratio, consumption share and value added rate are calculated from the extend I-O table. Direct tax rate, investment coefficient of SG, depreciation rate, saving rate and social discount rate are collected from Zhejiang government policy and reports (ZPBS, 2013; ZPDRC, 2016). Energy supply and demand coefficient are determined by the extend I-O table, relevant statistical yearbook and government report of Zhejiang province (ZPBS, 2013; ZPDRC, 2012; ZPEIC, 20122013 2015). GHG emission coefficient is calculated from statistical yearbook of China and Zhejiang and IPCC report (ZPBS, 2013; NBSC, 2013; IPCC, 2006). Core coefficients are presented in table 4 and table 5. 
Table 4. Value added rate, GHG emission coefficients and energy demand coefficients

\begin{tabular}{lccc}
\hline Category & Value added rate & $\begin{array}{l}\text { GHG emission coefficient } \\
(\mathrm{t} / \mathrm{CNY})\end{array}$ & $\begin{array}{l}\text { Energy demand coefficient } \\
\text { (Kwh/CNY) }\end{array}$ \\
\hline Farming & 0.627336 & 0.00000559 & 0.007932 \\
Light industry & 0.214462 & 0.00001582 & 0.022245 \\
Chemical & 0.185471 & 0.00003992 & 0.045838 \\
Non-metal & 0.222369 & 0.00003673 & 0.056993 \\
Metal & 0.180021 & 0.00011892 & 0.063717 \\
General equipment manufacturing & 0.236359 & 0.00000363 & 0.011450 \\
Electric equipment and machinery & 0.194476 & 0.00000363 & 0.012722 \\
Electronic equipment manufacturing & 0.226628 & 0.00000363 & 0.010177 \\
Construction & 0.228216 & 0.00000301 & 0.005059 \\
Transportation & 0.397034 & 0.00006464 & 0.009185 \\
Service \& others & 0.553015 & 0.00000549 & 0.008840 \\
Coal & 0.409546 & 0.00010210 & 0.044627 \\
Oil and petroleum & 0.152520 & 0.00050062 & 0.016316 \\
Fuel gas & 0.145245 & 0.00048961 & 0.009463 \\
Smart grid & 0.218103 & 0.00000000 & 0.009546 \\
Thermal power & 0.254266 & 0.00071248 & 0.086185 \\
Hydropower & 0.140423 & 0.00000000 & 0.079035 \\
Nuclear power & 0.319375 & 0.00000000 & 0.077550 \\
Solar power & 0.281234 & 0.00000000 & 0.061930 \\
Wind power & 0.444029 & 0.00000000 & 0.069190 \\
\hline
\end{tabular}

Table 5. Energy supply coefficients

Unit: Kwh/CNY

\begin{tabular}{llllll}
\hline Category & Thermal power & Nuclear power & Hydropower & Solar power & Wind power \\
\hline $\begin{array}{l}\text { Energy supply } \\
\text { coefficient }\end{array}$ & 0.708498611 & 0.708695883 & 0.708277087 & 0.49776008 & 0.718940392 \\
\hline
\end{tabular}

\section{Model}

\subsection{Material Flow Balance}

The material flow balance denotes the balance of supply and demand of products and service based on input-output table in monetary form. Perfect competition is assumed in this research. Therefore, the supply from all industrial sectors in left side of equation is meet the intermediate demand, government and private consumption, capital information and net export which is shown in equation 1-3. In the model, En indicates endogenous variable calculated by computer, and Ex is exogenous variable which is already given. Time span is from 2012 to 2030 .

$$
\begin{aligned}
& X_{u i}(t)=A_{u i u j} X_{u j}(t)+A_{u i c j} X_{c j}(t)+A_{u i e j j} X_{e j}(t)+C_{\mathrm{ui}}^{p}(t)+C_{\mathrm{ui}}^{g}(t) \\
& +Q_{u i u j} \Delta K_{\mathrm{uj}}(t)+Q_{u i c j} \Delta K_{\mathrm{cj}}(t)+Q_{u i e j} \Delta K_{\mathrm{ej}}(t)+N X_{\mathrm{ui}}(t) \\
& \quad X_{c i}(t)=A_{c i u j} X_{u j}(t)+A_{c i c j} X_{c j}(t)+A_{c i e j} X_{e j}(t)+C_{\mathrm{ci}}^{p}(t)+C_{\mathrm{ci}}^{g}(t) \\
& \quad+Q_{c i u j} \Delta K_{\mathrm{uj}}(t)+Q_{c i c j} \Delta K_{\mathrm{cj}}(t)+Q_{c i e j} \Delta K_{\mathrm{ej}}(t)+N X_{\mathrm{ci}}(t)
\end{aligned}
$$




$$
\begin{aligned}
& X_{e i}(t)=A_{e i u j} X_{u j}(t)+A_{e i c j} X_{c j}(t)+A_{e i e j} X_{e j}(t)+C_{e \mathrm{i}}^{p}(t)+C_{\mathrm{ei}}^{g}(t) \\
& +Q_{e i u j} \Delta K_{\mathrm{uj}}(t)+Q_{e i c j} \Delta K_{\mathrm{cj}}(t)+Q_{e i e j} \Delta K_{\mathrm{ej}}(t)+N X_{\mathrm{ei}}(t)
\end{aligned}
$$

$\mathrm{X}_{\mathrm{ui}}, \mathrm{X}_{\mathrm{ci}}, \mathrm{X}_{\mathrm{ei}}$ : output of usual industry $\mathrm{i}$ (conventional energy industry i, electricity industry $\mathrm{i}$ ), En $\mathrm{C}_{\mathrm{ui}}^{\mathrm{p}}, \mathrm{C}_{\mathrm{ci}}^{\mathrm{p}}, \mathrm{C}_{\mathrm{ei}}^{\mathrm{p}}$ : private consumption of usual industry i (conventional energy industry i, electricity industry $\mathrm{i}$ ), En $\mathrm{C}_{\mathrm{ui}}^{\mathrm{g}}, \mathrm{C}_{\mathrm{c}}^{\mathrm{g}}, \mathrm{C}_{\mathrm{e}}^{\mathrm{g}}$ : government consumption of usual industry i (conventional energy industry i, electricity industry i), En

$\Delta \mathrm{K}_{\mathrm{uj}}, \Delta \mathrm{K}_{\mathrm{cj}}, \Delta \mathrm{K}_{\mathrm{ej}}$ : gross investment of usual industry $\mathrm{j}$ (conventional energy industry $\mathrm{j}$, electricity industry $\mathrm{j}$ ), En $\mathrm{NX}_{\mathrm{ui}}, \mathrm{NX}_{\mathrm{ci}}, \mathrm{NX}_{\mathrm{ei}}$ : net export of usual industry i (conventional energy industry i, electricity industry i), En $A_{\text {uiuj }}, A_{\text {uicj }}, A_{\text {uiej }}$ : input coefficients from usual industry $i$ to usual industry $j$ (conventional energy industry $j$, electricity industry j), Ex

$A_{\text {ciuj }}, A_{\text {cicj }}, A_{\text {ciej }}$ : input coefficients from conventional energy industry $i$ to usual industry $j$ (conventional energy industry $\mathrm{j}$, electricity industry $\mathrm{j}$ ), Ex

$A_{\text {eiuj, }}, A_{\text {eicj }}, A_{\text {eiej: }}$ input coefficients from electricity industry $i$ to usual industry $j$ (conventional energy industry $j$, electricity industry j), Ex

$\mathrm{Q}_{\text {uiuj, }}, \mathrm{Quicj}_{\text {u }}, \mathrm{Quiej}_{\mathrm{i}}$ : input coefficients of capital stock formation from usual industry $\mathrm{i}$ to usual industry $\mathrm{j}$ (conventional energy industry $\mathrm{j}$, electricity industry j), Ex

$Q_{\text {ciuj, }}, Q_{\text {cicj, }}, Q_{\text {ciej }}$ : input coefficients of capital stock from conventional energy industry $i$ to usual industry $j$ (conventional energy industry $\mathrm{j}$, electricity industry j), Ex

$Q_{\text {eiuj, }}, Q_{\text {eicj }}$, $Q_{\text {eiej: }}$ input coefficients of capital stock from electricity industry i to usual industry $\mathrm{j}$ (conventional energy industry $\mathrm{j}$, electricity industry $\mathrm{j}$ ), Ex

\subsection{Value Flow Balance}

The value flow balance implies total input of industrial sector is sum of intermediate input and initial input including employer income, indirect tax, depreciation and business surplus based on perfect competitive assumption. Price rate is introduced to adjust price compared with base year for eliminating the effect of price fluctuation during the whole time horizon. Besides, Carbon tax is imposed on usual industry, conventional energy industry and thermal power industry according to their emission amount in equation 4,5 and 6 . Then all the carbon tax is subsidized to SG industry, solar power industry and wind power industry as shown in equation 7,8 and 9.

$$
\begin{aligned}
& \psi_{\mathrm{uj}}(t) X_{\mathrm{uj}}(t)=\sum \psi_{\mathrm{i}}(t) A_{j \mathrm{juj}} X_{\mathrm{uj}}(t)+\psi_{\mathrm{uj}} \gamma_{\mathrm{uj}} X_{\mathrm{uj}}(t)+\psi_{\mathrm{uj}} \tau_{\mathrm{uj}} X_{\mathrm{uj}}(t)+\psi_{\mathrm{uj} j} \delta_{\mathrm{uj}} K_{\mathrm{uj}}(t)+\tau_{c} \varepsilon_{\mathrm{uj}} X_{\mathrm{uj}}(t) \\
& \psi_{c j}(t) X_{\mathrm{cj}}(t)=\sum \psi_{\mathrm{i}}(t) A_{\mathrm{icj}} X_{\mathrm{ci}}(t)+\psi_{c j} \gamma_{\mathrm{cj}} X_{\mathrm{cj}}(t)+\psi_{c j} \tau_{c j} X_{c j}(t)+\psi_{c j} \delta_{\mathrm{cj}} K_{\mathrm{cj}}(t)+\tau_{c} \varepsilon_{c j} X_{c j}(t) \\
& \psi_{\mathrm{e}}(t) X_{e 2}(t)=\sum \psi_{\mathrm{i}}(t) A_{\mathrm{ie} 2} X_{\mathrm{e} 2}(t)+\psi_{\mathrm{e}} \gamma_{\mathrm{e} 2} X_{\mathrm{e} 2}(t)+\psi_{\mathrm{e}} \tau_{e 2} X_{\mathrm{e} 2}(t)+\psi_{\mathrm{e}} \delta_{\mathrm{e} 2} K_{\mathrm{e} 2}(t)+\tau_{c} \varepsilon_{e 2} X_{e 2}(t) \\
& \psi_{\mathrm{e}}(t) X_{e 1}(t)+S U_{e 1}(t)=\sum \psi_{\mathrm{i}}(t) A_{i e 1} X_{\mathrm{e} 1}(t)+\psi_{\mathrm{e}} \gamma_{\mathrm{e} 1} X_{\mathrm{e} 1}(t)+\psi_{\mathrm{e}} \tau_{e 1} X_{\mathrm{e} 1}(t)+\psi_{\mathrm{e}} \delta_{\mathrm{e} 1} K_{\mathrm{e} 1}(t) \\
& \psi_{\mathrm{e}}(t) X_{e 5}(t)+S U_{e 5}(t)=\sum \psi_{\mathrm{i}}(t) A_{i e 5} X_{\mathrm{e} 5}(t)+\psi_{\mathrm{e}} \gamma_{\mathrm{e} 5} X_{\mathrm{e} 5}(t)+\psi_{\mathrm{e}} \tau_{e 5} X_{\mathrm{e} 5}(t)+\psi_{\mathrm{e}} \delta_{e 5} K_{\mathrm{e} 5}(t) \\
& \psi_{\mathrm{e}}(t) X_{\mathrm{e} 6}(t)+S U_{e 6}(t)=\sum \psi_{\mathrm{i}}(t) A_{i e 6} X_{\mathrm{ee}}(t)+\psi_{\mathrm{e}} \gamma_{\mathrm{e} 6} X_{\mathrm{e} 6}(t)+\psi_{\mathrm{e}} \tau_{\mathrm{e} 6} X_{e 6}(t)+\psi_{\mathrm{e}} \delta_{e 6} K_{e 6}(t)
\end{aligned}
$$

$X_{\mathrm{uj}}, X_{\mathrm{cj}}$ : output of usual industry $\mathrm{j}$ (conventional energy industry $\mathrm{j}$ ), En

$\mathrm{X}_{\mathrm{e} 1}, \mathrm{X}_{\mathrm{e} 2}, \mathrm{X}_{\mathrm{e} 5}, \mathrm{X}_{\mathrm{e} 6}$ : output of electricity industry $1(2,5,6)$, En

$\mathrm{K}_{\mathrm{uj}}, \mathrm{K}_{\mathrm{cj}}$ : capital stock of usual industry $\mathrm{j}$ (conventional energy industry $\mathrm{j}$ ), En

$\mathrm{K}_{\mathrm{e} 1}, \mathrm{~K}_{\mathrm{e} 2}, \mathrm{~K}_{\mathrm{e} 5}, \mathrm{~K}_{\mathrm{e} 6}$ : capital stock of electricity industry $1(2,5,6)$, En

$A_{\text {iuj }}, A_{\text {icj: }}$ input coefficients from industry $i$ to usual industry $j$ (conventional energy industry j), Ex 
$A_{\text {iel } 1}, A_{\text {ie } 2}, A_{\text {ie } 5}, A_{\text {ie } 6}$ : input coefficients from industry i to electricity industry $1(2,5,6)$, Ex

$\psi_{\mathrm{i}}:$ price rate of industry $\mathrm{i}, \mathrm{En}$

$\psi_{\mathrm{uj}}, \psi_{\mathrm{cj}}$ : price rate of usual industry $\mathrm{j}$ (conventional energy industry $\mathrm{j}$ ), EN

$\psi_{\mathrm{e}}$ : price rate of electricity industry, En

$\gamma_{i}$ : income rate of industry i, Ex

$\gamma_{\mathrm{uj}}, \gamma_{\mathrm{cj}}$ : income rate of usual industry $\mathrm{j}$ (conventional energy industry $\mathrm{j}$ ), Ex

$\gamma_{\mathrm{e} 1}, \gamma_{\mathrm{e} 2}, \gamma_{\mathrm{e} 5}, \gamma_{\mathrm{ee}}$ : income rate of electricity industry $1(2,5,6)$, Ex

$\tau_{\mathrm{uj}}, \tau_{\mathrm{cj}}$ : indirect tax rate of usual industry $\mathrm{j}$ (conventional energy industry $\mathrm{j}$ ), Ex

$\tau_{\mathrm{e} 1}, \tau_{\mathrm{e} 2}, \tau_{\mathrm{e} 5}, \tau_{\mathrm{e} 6}$ : indirect tax rate of electricity industry $1(2,5,6), \mathrm{Ex}$

$\delta_{\mathrm{uj}}, \delta_{\mathrm{cj}}$ : capital depreciation rate of usual industry $\mathrm{j}$ (conventional energy industry $\mathrm{j}$ ), Ex

$\delta_{\mathrm{e} 1}, \delta_{\mathrm{e} 2}, \delta_{\mathrm{e} 5}, \delta_{\mathrm{e} 6}$ : capital depreciation rate of electricity industry $1(2,5,6)$, Ex

$\tau_{\mathrm{c}:}$ carbon emission tax rate, Ex

$\varepsilon_{\mathrm{uj}}, \varepsilon_{\mathrm{cj}}$ : carbon emission coefficient of usual industry $\mathrm{j}$ (conventional energy industry $\mathrm{j}$ ), Ex

$\varepsilon_{\mathrm{e} 2}$ : carbon emission coefficient of electricity industry $2, \mathrm{Ex}$

$\mathrm{SU}_{\mathrm{e} 1}, \mathrm{SU}_{\mathrm{e} 5}, \mathrm{SU}_{\mathrm{e} 6}$ : subsidy for electricity industry $1(5,6)$, En

\subsection{Energy Flow Balance}

Equation 10 presents energy supply plus net import meet energy demand. Energy supply is composed of five power generation which is dependent with their output that is shown in equation 11 and 12. Energy demand of usual industry and conventional energy industry is related to their output in equation 13. Energy demand of private and government is related to their consumption in equation 14 and 15. Equation 16 shows energy demand is sum of demand of usual industry, conventional energy industry, private and government.

$$
\begin{gathered}
E S(t)+E N(t)=E D(t) \\
E S(\mathrm{t})=\sum_{i=2}^{6} E S_{e i}(t) \\
E S_{e i}(t)=\zeta_{i} X_{e i}(t) \\
E D_{i}(t)=\varsigma_{\mathrm{i}} X_{i}(t) \\
E D^{p}(t)=\varsigma^{p} \sum_{\mathrm{i}=1}^{21} C_{i}^{p}(t) \\
E D^{g}(t)=\varsigma^{g} \sum_{i=1}^{21} C_{i}^{g}(t) \\
E D(t)=\sum_{i=1}^{11} E D_{u i}(t)+\sum_{i=1}^{3} E D_{c i}(t)+E D^{p}(t)+E D^{g}(t)
\end{gathered}
$$

ES: amount of electricity supply, En

EN: net import or export amount of electricity, En

ED: amount of electricity demand, En

$E_{\mathrm{ei}}$ : amount of electricity supply of electricity industry i, En

$\mathrm{X}_{\mathrm{ei}}$ : output of electricity industry $\mathrm{i}, \mathrm{En}$ 
$E D_{\mathrm{i}}$ : amount of electricity demand of industry i, En

$\mathrm{X}_{\mathrm{i}}$ : output of industry i, En

$\mathrm{ED}^{\mathrm{p}}$ : electricity demand of private sector, En

$\mathrm{C}_{\mathrm{i}}^{\mathrm{p}}$ : private consumption of industry $\mathrm{i}$, En

$\mathrm{ED}^{\mathrm{g}}$ : electricity demand of government sector, En

$\mathrm{C}_{\mathrm{i}}^{\mathrm{g}}$ : government consumption of industry i, En

$\zeta_{i}$ : energy supply coefficient of electricity industry i, Ex

$\varsigma_{i}$ : energy demand coefficient of industry $i$, Ex

$\varsigma^{\mathrm{p}}$ : energy demand coefficient of private sector, Ex

$\varsigma^{\mathrm{g}}$ : energy demand coefficient of government sector, Ex

\subsection{Power Supply and Demand}

Power supply and demand vary on account of applying SG. Power demand is categorized according to electricity stability. The power demand under static stability (B1) is sum of demand of $u 2$, $u 7$ and $u 8$ in the usual industry as shown in equation 17. Equation 18 expresses the power demand under B2 is sum demand of u3-u6 in the usual industry and private sector. The power demand under B3 is sum of demand of $u 1, u 9, u 10$ and $u 11$ in the usual industry in equation 19. Meanwhile, power demand is no more than power supply from five power generation under the three electricity stability which is shown in equation 20-22 due to assumption of supply and demand balance. Power supply is also relevant to investment of SG in five power generation industry under the three electricity stability that is shown in equation 23-25.

$$
\begin{gathered}
E D^{\mathrm{b} 1}(t)=E D_{u 2}(t)+E D_{u 7}(t)+E D_{u 8}(t) \\
E D^{b 2}(t)=E D_{u 3}(t)+E D_{u 4}(t)+E D_{u 5}(t)+E D_{u 6}(t)+E D^{p}(t) \\
E D^{\mathrm{b} 3}(t)=E D_{u 1}(t)+E D_{u 9}(t)+E D_{u 10}(t)+E D_{u 11}(t) \\
E D^{\mathrm{b} 1}(t)<=\sum_{i=2}^{6} E S_{e i}^{b 1}(t) \\
E D^{\mathrm{b} 2}(t)<=\sum_{i=2}^{6} E S_{e i}^{b 2}(t) \\
E D^{\mathrm{b} 3}(t)<=\sum_{i=2}^{6} E S_{e i}^{b 3}(t) \\
K S^{\mathrm{b} 1}(t)=\eta^{b 1} \sum_{i=2}^{6} E S_{e i}^{b 1}(t) \\
K S^{\mathrm{b} 2}(t)=\eta^{b 2} \sum_{i=2}^{6} E S_{e i}^{b 2}(t) \\
K S^{\mathrm{b} 3}(t)=\eta^{b 3} \sum_{i=2}^{6} E S_{e i}^{b 3}(t)
\end{gathered}
$$

$\mathrm{ED}^{\mathrm{bj}}$ : electricity demand under electricity stability $\mathrm{Bj}, \mathrm{En}$

$\mathrm{ED}_{\mathrm{ui}}$ : amount of electricity demand of usual industry $\mathrm{i}, \mathrm{En}$

$\mathrm{ES}_{\mathrm{ei}}^{\mathrm{bj}}$ : electricity supply of electricity industry i under electricity stability Bj, En

$\mathrm{KS}^{\mathrm{bj}}$ : capital stock of SG under electricity stability Bj, En

$\eta^{\text {bj }}$ : investment coefficient of SG under electricity stability Bj, Ex

\subsection{Capital Stock and Increment}

Capital stock of each industry is linearly relevant to its output due to linear assumption in equation 26. Equation 27 shows the total investment and net export are entirely from private saving and government saving. Social 
economy is driven by capital investment. Therefore, capital stock in term $t+1$ is accumulated by net investment and capital stock in term $\mathrm{t}$ which is shown in equation 28 .

$$
\begin{gathered}
X_{i}(t)=\varphi_{i} K_{i}(t) \\
\sum\left\{\Delta K_{i}(t)-\delta_{i} K_{i}(t)+N X_{i}(t)\right\}=S^{p}(t)+S^{g}(t) \\
K_{i}(t+1)=\left(1-\delta_{i}\right) K_{i}(t)+\Delta K_{i}(t)
\end{gathered}
$$

$\mathrm{X}_{\mathrm{i}}$ : output of industry i, En

$\mathrm{K}_{\mathrm{i}}$ : capital stock of industry i, En

$\varphi_{\mathrm{i}}$ : capital output ratio of industry $\mathrm{i}, \mathrm{Ex}$

$\Delta \mathrm{K}_{\mathrm{i}}$ : gross investment of industry $\mathrm{i}, \mathrm{En}$

$\delta_{\mathrm{i}}$ : capital depreciation rate of industry $i, \mathrm{Ex}$

$\mathrm{NX}_{\mathrm{i}}$ : net export of industry $\mathrm{i}$, En

$S^{p}$ : private saving, En

$S^{\mathrm{g}}$ : government saving, En

\subsection{Private Income, Saving and Consumption}

Equation 29 indicates disposable income is sum of employer income excluding direct tax. In addition, disposable income consists of private saving and consumption according to Cobb-Douglas utility function. So equation 30 and 31 display saving and consumption are in proportion to disposable income. On this basis, sum of saving rate and consumption share is 1 in equation 32 .

$$
\begin{gathered}
Y_{d}(t)=\left(1-\tau_{d}\right) \sum \gamma_{i} X_{\mathrm{i}}(t) \\
S^{p}(t)=\beta Y_{d}(t) \\
\psi_{i}(t) C_{i}^{p}(t)=Y_{d}(t) \alpha_{\mathrm{i}} \\
\sum \alpha_{\mathrm{i}}+\beta=1
\end{gathered}
$$

$Y_{\mathrm{d}}$ : disposable income, En

$\tau_{\mathrm{d}}$ direct tax rate, Ex

$\gamma_{\mathrm{i}}$ : income rate of industry $\mathrm{i}, \mathrm{Ex}$

$\mathrm{X}_{\mathrm{i}}$ : output of industry $\mathrm{i}$, En

$\mathrm{S}^{\mathrm{p}}$ : private saving, En

$\beta$ : saving rate, Ex

$\mathrm{C}_{\mathrm{i}}^{\mathrm{p}}$ : private consumption of industry $\mathrm{i}$, En

$\alpha_{\mathrm{i}}$ : consumption share of industry i, Ex

\subsection{Government Revenue and Expenditure}

Government revenue is composed of indirect tax, direct tax and carbon tax as shown in the left side of equation 33. The right side is government expenditure which consists of government consumption, government saving and subsidy for SG, solar power and wind power. Especially, equation 34 denotes all carbon tax is expend in subsidy for SG, solar power and wind power.

$$
\begin{aligned}
& \sum \tau_{\mathrm{i}} X_{\mathrm{i}}(t)+\tau_{d} \sum \gamma_{\mathrm{i}} X_{i}(t)+\tau_{c} \sum \varepsilon_{\mathrm{ui}} X_{\mathrm{ui}}(t)+\tau_{c} \sum \varepsilon_{\mathrm{ci}} X_{\mathrm{ci}}(t)+\tau_{c} \varepsilon_{\mathrm{e} 2} X_{\mathrm{e} 2}(t) \\
& =\sum C_{i}^{g}+S^{g}(t)+S U_{e 1}(t)+S U_{e 5}(t)+S U_{e 6}(t)
\end{aligned}
$$




$$
\tau_{c} \sum \varepsilon_{\mathrm{ui}} X_{\mathrm{ui}}(t)+\tau_{c} \sum \varepsilon_{\mathrm{ci}} X_{\mathrm{ci}}(t)+\tau_{c} \mathcal{E}_{\mathrm{e} 2} X_{\mathrm{e} 2}(t)=S U_{e 1}(t)+S U_{e 5}(t)+S U_{e 6}(t)
$$

$\mathrm{X}_{\mathrm{i}}$ : output of industry $\mathrm{i}$, En

$\tau_{\mathrm{i}}$ indirect tax rate of industry $\mathrm{i}, \mathrm{Ex}$

$\tau_{\mathrm{d}}$ ' direct tax rate, Ex

$\tau_{\mathrm{c}:}$ carbon emission tax rate, Ex

$\varepsilon_{\text {ui: }}$ carbon emission coefficient of usual industry i, Ex

$\varepsilon_{\mathrm{ci}}$ carbon emission coefficient of conventional energy industry i, Ex

$\varepsilon_{\mathrm{e} 2}$ carbon emission coefficient of electricity industry $2, \mathrm{Ex}$

$\mathrm{C}_{\mathrm{i}}^{\mathrm{g}}$ : government consumption of industry $\mathrm{i}$, En

$\mathrm{S}^{\mathrm{g}}$ : government saving, En

$\mathrm{SU}_{\mathrm{ei}}$ : subsidy for electricity industry i, En

\subsection{GHG Emission}

Equation 35 shows GHG emits from usual industry, conventional energy industry, thermal power industry, private consumption and government consumption. Emission limitation is presented in equation 36 in order to preset GHG emission target in different scenarios.

$$
\begin{gathered}
G E(t)=\sum \varepsilon_{u i} X_{u i}(t)+\sum \varepsilon_{c i} X_{c i}(t)+\varepsilon_{e 2} X_{e 2}(t)+\varepsilon_{p} \sum C_{\mathrm{i}}^{\mathrm{p}}(\mathrm{t})+\varepsilon_{\mathrm{g}} \sum \mathrm{C}_{\mathrm{i}}^{\mathrm{g}}(\mathrm{t}) \\
\sum_{\mathrm{t}=1}^{19} G E(t) \leq(1-\mu) \sum_{t=1}^{19} \overline{G E}(t)
\end{gathered}
$$

GE: total GHG emission amount, En

$\mathrm{X}_{\mathrm{i}}$ : output of industry i, En

$\varepsilon_{\text {ui: }}$ carbon emission coefficient of usual industry i, Ex

$\varepsilon_{\text {ci: }}$ carbon emission coefficient of conventional energy industry i, Ex

$\varepsilon_{\mathrm{e} 2}$ carbon emission coefficient of electricity industry 2, Ex

$\varepsilon_{\mathrm{p}}, \varepsilon_{\mathrm{g}}$ : carbon emission coefficient of private sector (government sector), Ex

$\overline{\mathrm{GE}}$ : GHG emission limitation, Ex

$\mu$ : carbon emission reduction rate, Ex

\subsection{Objective Function}

Maximizing growth of Gross Regional Product (GRP) is set as objective in this research to evaluate the economic growth from 2012 to 2030 as shown in equation 37. Social discount rate is introduced as exogenous variable in view of the benefit in the future. In addition, GRP is sum of value added of each industry which is determined by value added rate and output which is shown in equation 38 .

$$
\begin{gathered}
\operatorname{Max} \sum_{t=1}^{19} \frac{1}{(1+\rho)^{t-1}} \operatorname{GRP}(t) \\
\operatorname{GRP}(t)=\sum \mathrm{v}_{i} X_{i}(t)
\end{gathered}
$$

GRP: gross regional product, En

$\rho$ :social discount rate, Ex

$\mathrm{v}_{\mathrm{i}}$ : value added rate of industry $\mathrm{i}, \mathrm{Ex}$

$\mathrm{X}_{\mathrm{i}}$ : output of industry i, En 


\section{Results Analysis}

\subsection{Economic Growth and GHG Emission}

GHG emission continuously increases along with economy growth as shown in Figure 2. GRP grows to 10,263.7 billion Chinese Yuan (CNY) at average annual growth rate (AAGR) of $6.0 \%$ (See table 6) while GHG emits 1.87 billion tons in 2030 in S0, which reflects real economic growth and GHG emission without any policy implementation. In S1, GRP grows to 9731.3 billion CNY at AAGR of 5.7\%, and GHG emits 1.6 billion tons. It means GRP growth decline by $5.2 \%$ in 2030 meanwhile AAGR falls by $5 \%$ under the emission reduction target of $10 \%$ based on S0. For achieving the emission reduction target of $20 \%$, GRP grows to 8983.9 billion CNY at AAGR of 5.2\% and GHG emission increases to 1.1 billion tons in 2030 in S2. The GRP growth further decline compare to S0 by $12.5 \%$ when AAGR falls by $13.3 \%$. In S3, GRP grows to 7984.7 billion CNY at AAGR of $4.5 \%$, whereas GHG merely emits 1.0 billion tons in 2030 under the emission reduction target of $30 \%$. The GRP growth drops as many as $22.2 \%$ in 2030 while AAGR falls by $33.3 \%$ compare with S0, which has maximum decline in all the scenarios.

Table 6. AAGR of GRP

Unit: \%

\begin{tabular}{lllll}
\hline & S0 & S1 & S2 & S3 \\
\hline AAGR & 6 & 5.7 & 5.2 & 4.5 \\
Decline in AAGR & & 5 & 13.3 & 33.3 \\
\hline
\end{tabular}

Note. AAGR is average annual growth rate.

In particular, GHG emits to peak in 2029 in S1 which means it emits 1.6 billion tons in both 2029 and 2030. In S2, it emits to peak in 2027 which shows it annually emits 1.1 billion tons in 2027-2030. In S3, its emission peak is achieved much earlier to 2025 that displays it annually emits 1.0 billion tons from 2025 to 2030 . The change of GRP growth and GHG emission reveals economy slows down on account of imposing carbon tax under emission mitigation target. And economic growth severely declines due to higher carbon tax rate and stricter emission constraint. Moreover, implementing different policy of carbon tax and subsidy for SG and renewable power has significantly distinctive effect on emission mitigation.

\subsection{Total Power Demand and Supply}

Total power demand between 2012 and 2030 is 10.7 trillion Kwh, and total power supply is 9.6 trillion Kwh in S0 which is illustrated in Figure 3. In S1, total power demand decreases to 10.4 trillion Kwh, while total power supply increases to 9.83 trillion Kwh. Power import reduces by $48.5 \%$ compare to S0. Total power demand decreases to 10.3 trillion Kwh, whereas total power supply increases to 9.88 trillion Kwh in S2. Power import further reduces by $62.3 \%$ compare with S0. The most remarkable change occurs in S3 where total power demand is 10.28 trillion Kwh, and total power supply is 9.9 trillion Kwh. Accordingly, power import reduces as much as $66 \%$ compare to S0. It implies that total power demand continuously decreases with the decline in economic growth. On the contrary, total power supply is rising as SG, solar power and wind power are accumulatively subsidized to attain rapid development. The imbalance between power demand and supply is alleviated since solar power and wind power are subsidized to increase power supply, and development of SG improves the efficiency of total power supply. Moreover, the optimal effect is presented in S3 due to most subsidy for SG, solar power and wind power.

\subsection{Carbon Tax and Subsidy}

Figure. 4 denotes combination policy of carbon tax and subsidy is implemented for the sake of achieving different emission target. S0 is BAU without any implementation of policy under zero emission constraint. In S1, carbon tax rate is $44.7 \mathrm{CNY} /$ ton by the simulation. Total subsidy for SG, solar power and wind power are 519.1, 152.3 and 319.4 billion CNY respectively in order to reduce GHG emission by $10 \%$. Under the emission target of $20 \%$ in S2, carbon tax rate is required to $51.7 \mathrm{CNY} /$ ton, 531.9, 219.4 and 322.4 billion CNY are subsidized to $\mathrm{SG}$, solar power and wind power respectively. For the sake of reducing GHG emission by $30 \%$, carbon tax of 78.1 CNY/ton is imposed in S3. SG, solar power and wind power are subsidized by 598.1, 295.5 and 325.7 billion CNY, respectively. It uncovers, on the one hand, GHG emission mitigates when all the industrial sectors are imposed by carbon tax to constraint output. On the other hand, SG, solar power and wind power need to be increasingly subsidized for more emission reduction. Furthermore, the optimal policy of carbon tax and subsidy is implemented in $\mathrm{S} 3$ as it realizes the maximum emission reduction. 


\subsection{Output of Electricity Industry}

Output change of electricity industry is displayed in table 7. In S1, SG, thermal power, solar power and wind power annually grow at $7.1 \%, 3.95 \%, 53.7 \%$ and $32 \%$ respectively. SG, solar power and wind power grow at AAGR of $8 \%, 56.7 \%$ and $33.5 \%$ respectively in S2. However, AAGR of thermal power fall to $3.56 \%$. S3 shows SG, solar power and wind power have highest AAGR of $9.1 \%, 59 \%$ and $35.1 \%$ respectively, whereas thermal power merely annually grows at $2.95 \%$. Accordingly, output structure of electricity industry changes in 2030 which is illustrated in Figure 5. SG, solar power and wind power account for 8.3\%. 7.6\% and $13.2 \%$ respectively in S1.Their share increases to $9.2 \%, 10.2 \%$ and $15.4 \%$ respectively in S2. In S3, they occupy $10.8 \%, 12.7 \%$ and $18.6 \%$ of total output respectively. Contrarily, share of thermal power fall from $53.1 \%$ in S1 to $47.3 \%$ in S2, and finally to $41.8 \%$ in S3. It explains output of electricity industry changes due to different policy implementation. Eventually, output structure of electricity industry is transformed along with output change. SG, solar power and wind power continuously grow while the growth of thermal power falls off, and the output structure is notably optimized in S3.

Table 7. AAGR of output of electricity industry

Unit: \%

\begin{tabular}{lllll}
\hline & Smart grid & Thermal power & Solar power & Wind power \\
\hline S1 & 7.1 & 3.95 & 53.7 & 32 \\
S2 & 8 & 3.56 & 56.7 & 33.5 \\
S3 & 9.1 & 2.95 & 59 & 35.1 \\
\hline
\end{tabular}

Note. AAGR is average annual growth rate.

\subsection{Power Supply Structure}

Power supply structure in 2030 is shown in Figure 6. In S0, thermal power, solar power and wind power account for $79.8 \%, 0.02 \%$ and $0.28 \%$ of total power supply respectively. Solar power and wind power increase to $6 \%$ and $15 \%$, whereas thermal power decreases to $59.2 \%$ in S1. In S2, solar power and wind power further increase to $8.2 \%$ and $17.8 \%$, while thermal power continues to decrease to $53.7 \%$. Solar power and wind power increase as much as $10.4 \%$ and $22 \%$ in $\mathrm{S} 3$, when thermal power decreases to minimum of $48.8 \%$. It implies conventional energy consumption takes up extremely high proportion in energy structure without any policy implementation. It is obviously reduced with increase on renewable energy usage including solar power and wind power. Application of solar power and wind power is expanded due to sustained policy support. And ultimately, the entire structure of power supply is transformed since differentiated policy is implemented. Similarly, S3 presents its optimal structure of power supply among all the scenarios.

\subsection{Power Supply under Different Electricity Stability}

Table 8 shows the Average annual increase rate (AAIR) of power supply under static stability. In S1, thermal power, solar power and wind power averagely increase at $56.7 \%, 44.6 \%$ and $40.4 \%$ respectively. AAIR of solar power rises to $47.4 \%$, but thermal power and wind power fall to $53.5 \%$ and $25.6 \%$ in S2. In S3, AAIR of thermal power falls to $2.8 \%$, while solar power and wind power continuously increase to $49.3 \%$ and $43.7 \%$. Accordingly, power supply structure under static stability in 2030 changes as well which is illustrated in Figure 7. In S1, thermal power, solar power and wind power account for $74.3 \%, 7.4 \%$ and $18.3 \%$ of power supply respectively. The share of thermal power falls to $74.4 \%$ in S2, and $47.6 \%$ in S3. On the contrary, solar power and wind power rise up to $7.8 \%$ and $16.8 \%$ in S2, then $17 \%$ and $35.5 \%$ in S3. It reveals solar power and wind power significantly substitute thermal power under static stability. Especially, power supply structure is apparently optimized under static stability in $\mathrm{S} 3$ by reason of SG introduction.

Nevertheless, power supply fiercely fluctuates under dynamic stability I (See Table 8). Thermal power and wind power averagely increase at $0.6 \%$ and $25.2 \%$ in S1. Thermal power negatively increases at $94.3 \%$ in S2, and at $4 \%$ in S3. Wind power averagely increases at $28 \%$ in S3, and its AAIR is default in S2 as well as solar power in all the scenarios due to their supply are zero in base year. Figure 8 displays the power supply structure under dynamic stability I in 2030. In S1, Thermal power, solar power and wind power account for $51.1 \%, 3.7 \%$ and $9.6 \%$ respectively. Thermal power decreases to $22.9 \%$, while solar power and wind power increase to $7.4 \%$ and $16.4 \%$ in S2. However, thermal power increases to $56.8 \%$, when solar power and wind power decrease to $5.2 \%$ and $11.4 \%$ in S3. It uncovers thermal power as well as nuclear power and hydro power is mainly used under dynamic stability I. The substitutive effect of solar power and wind power on thermal power is 
remarkable in S2. So both insufficient and excessive policy causes inefficiency under dynamic stability I, and the optimal policy effect is in S2 instead of in S3.

Table 8. AAIR of power supply

Unit: \%

\begin{tabular}{llllllllll}
\hline & \multicolumn{3}{c}{ Thermal power } & \multicolumn{3}{c}{ Solar power } & \multicolumn{3}{c}{ Wind power } \\
\hline & S1 & S2 & S3 & S1 & S2 & S3 & S1 & S2 & S3 \\
B1 & 56.7 & 53.5 & 2.8 & 44.6 & 47.4 & 49.3 & 40.4 & 25.6 & 43.7 \\
B2 & 0.6 & -94.3 & 4 & -- & -- & -- & 25.2 & -- & 28 \\
B3 & 5.4 & 8.5 & -94.6 & -- & -- & -- & 211.1 & -- & 216 \\
\hline
\end{tabular}

Note. AAIR is average annual increase rate; "-94.3" indicates decrease at average rate of 94.3\%;

"--" indicates default data as it is zero in base year.

Likewise, power supply varies drastically under dynamic stability II (See table 8 ). Thermal power averagely increases at $5.4 \%$ in $\mathrm{S} 1$ and $8.5 \%$ in S2. In contrast, it negatively increases at $94.6 \%$ in S3. Wind power averagely increase at $211.1 \%$ in S2 and $216 \%$ in S3. AAIR of solar power and wind power in S2 is default. Finally, power supply structure under dynamic stability II in 2030 changes as shown in Figure 9. In S1, thermal power, solar power and wind power account for $61 \%, 10.4 \%$ and $25.5 \%$ respectively. In S2, thermal power increases to $68 \%$ while solar power and wind power fall to $9.7 \%$ and $21 \%$. Nonetheless, thermal power drops sharply to $12 \%$, when solar power and wind power rise to $25.6 \%$ and $53.4 \%$ in S3. It demonstrates that solar power and wind power, rather than thermal power are widely used under dynamic stability II along with the continuous policy support, although it has negative effect in S2. Hence, power supply structure under dynamic stability II is significantly optimized in S3.

\section{Conclusion and Suggestion}

China once again promises to peak carbon dioxides emission at emission intensity by $60-65 \%$ below 2005 levels, and increase the share of non-fossil energy of the primary energy to $20 \%$ by 2030 in Paris Agreement. Making widely use renewable energy to optimize energy structure is regarded as efficient approach to mitigate GHG emission. Even so, it is inevitable that improving energy efficiency is still one of core issues in energy utilization. Both SG and renewable energy are collectively introduced in this research in order to analyze their effect of economic growth, energy supply and demand and environmental improvement. Power supply and demand model is constructed to analyze the effect of SG introduction on power supply structure, total power supply and demand. Comprehensive model is constructed to evaluate the impact of introducing SG and renewable energy on economic growth and environmental improvement under different emission limitation. In the research, I-O simulation model is applied to make dynamic analysis based on extend regional I-O framework. GRP maximization is set as objective to comparatively analyze GRP growth, energy supply and demand and GHG emission in four scenarios. Several conclusions can be drawn as follow:

(1) Emission mitigation target can be achieved by means of implementation of combination policy. Carbon tax is imposed on industrial sectors in order to directly mitigate GHG emission from production process. All the carbon tax is subsidized to SG and renewable energy to promote development of electricity industry and change structure of energy supply and demand. Carbon tax of 78.1CNY/ton and total subsidy of 1,219.3 billion CNY are implemented in S3 so that its GHG emission has most significant reduction comparing to other scenarios.

(2) Introducing SG and renewable energy ultimately fulfill energy structure optimization and efficiency improvement. Renewable energy instead of conventional energy is used in large-scale so as to reduce GHG emission directly. Renewable energy usage including solar power and wind power accounts for $31.3 \%$ while thermal power falls to $41.8 \%$ in S3. What's more, considering electricity stability, SG is developed to improve energy efficiency among usual industries. Renewable energy supplies $52.5 \%$ of power under static stability, $16.6 \%$ under dynamic stability I and 79\% under dynamic stability II in S3, which is optimal supply structure in all the scenarios.

(3) Output structure of electricity industry is improved despite slowdown of economic growth. Due to continuous subsidy, SG and renewable energy grow fast in all the scenarios. Nonetheless, growth of thermal power gradually decelerates by reason of increase on carbon tax. This improvement is particularly verified in S3, where SG and renewable energy account for $42.1 \%$ of total output while thermal power falls to $41.8 \%$. Similarly, 
growth of usual industry and conventional energy industry also slows down because of carbon tax constraint in S1-S3 compare with S0. Especially, GRP merely grows to 7984.7 billion CNY in S3 that is minimum growth in all scenarios.

(4) This simulation research comprehensively assesses economic growth, energy supply and demand and environment impact. The optimal policy can be selected by comparative analysis. Obviously, mitigating GHG emission has to be at the cost of economic slowdown. GHG emission is cut down most in S3 even though GRP growth is minimum. Additionally, both energy structure and efficiency play an import role in GHG emission mitigation, so energy supply and demand under different electricity stability need be taken into account as well.

It is strongly necessary for planner or decision maker to thoroughly consider policy targets and effects. S3 can be regarded as optimal policy because it minimizes GHG emission, optimizes energy supply structure and finally achieves trade-off between economic growth and environmental improvement. In addition, more attention need to be paid to SG and renewable energy. Future work could be possibly focus on sustainable and effective utilization of hybrid energy in SG even in micro-grid, and spillover effects of SG and renewable energy on regional economic growth under environmental constraint with implementation of new policies.

\section{Acknowledgements}

This research was supported by University of Tsukuba through the Research Assistant work, and also by the Research Group at Circular Economy, Transformation and Development of Zhejiang, Jiaxing University, Zhejiang, China.

\section{References}

Amri, F. (2017). The relationship amongst energy consumption (renewable and nonrenewable), and GDP in Algeria. Renewable and Sustainable Energy Reviews, 76, 62-71. https://doi.org/10.1016/j.rser.2017.03.029

Avril, S., Mansilla, C., Busson, M., \& Lemaire, T. (2012). Photovoltaic energy policy: Financial estimation and performance comparison of the public support in five representative countries. Energy Policy, 51, $244-258$. https://doi.org/10.1016/j.enpol.2012.07.050

Baghdadi, F., Mohammedi, K., Diaf, S., \& Behar, O. (2015). Feasibility study and energy conversion analysis of stand-alone hybrid renewable energy system. Energy Conversion and Management, 105, 471-479. https://doi.org/10.1016/j.enconman.2015.07.051

Bernal, A. P., dos Santos, I. F. S., Silva, A. P. M., Barros, R. M., \& Ribeiro, E. M. (2017).Vinasse biogas for energy generation in Brazil: An assessment of economic feasibility, energy potential and avoided $\mathrm{CO} 2$ emissions. Journal of Cleaner Production, 151, 260-271. https://doi.org/10.1016/j.jclepro.2017.03.064

China Electricity Council (CEC). (2013). China Electric Power Yearbook 2013. China.

Conti, S., \& Rizzo, S. A. (2014). Probability of adequacy evaluation considering power output correlation of renewable generators in SGs. Electrical Power and Energy Systems, 61, $145-151$. https://doi.org/10.1016/j.ijepes.2014.03.042

Danish, Zhang, B., Wang, B., \& Wang, Z. H. (2017). Role of renewable energy and non-renewable energy consumption on EKC: Evidence from Pakistan. Journal of Cleaner Production 156, 855-864. https://doi.org/10.1016/j.jclepro.2017.03.203

Dogan, E., \& Seker, F. (2016). Determinants of $\mathrm{CO}_{2}$ emissions in the European Union: The role of renewable and non-renewable energy. Renewable Energy, 94, 429-439. https://doi.org/10.1016/j.renene.2016.03.078

Friedlingstein, P., Andrew, R. M., Rogelj, J., Peters, G. P., Canadell, J. G., Knutti, R. ...Le Quéré, C. (2014). Persistent growth of $\mathrm{CO}_{2}$ emissions and implications for reaching climate targets. Nature Geoscience, 7, 709-715. https://doi.org/10.1038/ngeo2248

Haidar, A. M. A., Muttaqi, K., \& Sutanto, D. (2015). SG and its future perspectives in Australia. Renewable and Sustainable Energy Reviews, 51, 1375-1389. https://doi.org/10.1016/j.rser.2015.07.040

Hossain, M. S., Madlool, N. A., Rahim, N. A., Selvaraj, J., Pandey, A. K., \& Khan, A. F. (2016). Role of SG in renewable energy: An overview. Renewable and Sustainable Energy Reviews, 60, 1168-1184. https://doi.org/10.1016/j.rser.2015.09.098

International Energy Agency (IEA). (2016). Word Energy Outlook 2016. Pairs, France.

IPCC. (2006). 2006 IPCC Guidelines for National Greenhouse Gas Inventories. IGES, Japan.

IqtiyaniIlham, N., Hasanuzzaman, M., \& Hosenuzzaman, M. (2017). European SG prospects, policies, and 
challenges. Renewable and Sustainable Energy Reviews, 67, 776-790. https://doi.org/10.1016/j.rser.2016.09.014

Leontief, W. W. (1936). Quantitative input and output relations in the economic systems of the United States. Rev Econ Stat, 105-125. https://doi.org/10.2307/1927837

Lu, K. Y., Zhu, Y. C., Li, Z. L., Singh, R. K., \& Nozaki, N. (2016). Dynamic Simulation Assessment of Environment Friendly Vehicles Introduction and Clean Energy Promotion Policy in China. Journal of Sustainable Development, 9(5). https://doi.org/10.5539/jsd.v9n5p83

Martins, F. (2017). PV sector in the European Union countries - Clusters and efficiency. Renewable and Sustainable Energy Reviews, 74, 173-177. https://doi.org/10.1016/j.rser.2017.02.026

Mirza, F. M., \& Kanwal, A. (2017). Energy consumption, carbon emissions and economic growth in Pakistan: Dynamic causality analysis. Renewable and Sustainable Energy Reviews, 72, 1233-1240. https://doi.org/10.1016/j.rser.2016.10.081

National Bureau of Statistics of China (NBSC). (2013). China Energy Statistical Yearbook 2013. China.

Nijkamp, P. (1977). Theory and application of environmental economics. Plos One.

Pazheri, F. R. (2015). Tri-generation based hybrid power plant scheduling for renewable resources rich area with energy storage. Energy Conversion and Management, 103, 717-725. https://doi.org/10.1016/j.enconman.2015.07.023

Petrillo, A., De Felice, F., Jannelli, E., Autorino, C., Minutillo, M., \& Lavadera, A. L. (2016). Life cycle assessment (LCA) and life cycle cost (LCC) analysis model for a stand-alone hybrid renewable energy system. Renewable Energy, 95, 337-355. https://doi.org/10.1016/j.renene.2016.04.027

Rescha, M., Bühlera, J., Klausena, M., \& Sumperb, A. (2017). Impact of operation strategies of large scale battery systems on distribution grid planning in Germany. Renewable and Sustainable Energy Reviews, 74, 1042-1063. https://doi.org/10.1016/j.rser.2017.02.075

Song, J. N., Yang, W., Higano, Y., \& Wang, X. E. (2015). Introducing renewable energy and industrial restructuring to reduce GHG emission: Application of a dynamic sim-ulation model. Energy Conversion and Management, 96, 625-636. https://doi.org/10.1016/j.enconman.2015.03.024

Sun, P., \& Nie, P.-Y. (2015). A comparative study of feed-in tariff and renewable portfolio standard policy in renewable energy industry. Renewable Energy, 74, 255-262. https://doi.org/10.1016/j.renene.2014.08.027

Tuballa, M. L., \& Abundo, M. L. (2016). A review of the development of SG technologies. Renewable and Sustainable Energy Reviews, 59, 710-725. https://doi.org/10.1016/j.rser.2016.01.011

United States Department of Energy Office of Electric Transmission and Distribution. (2003). "Grid 2030” A NATIONAL VISION FOR ELECTRICITY'S SECOND 100 YEARS.

Vardakas, J. S., Zorba, N., \& Verikoukis, C. V. (2015). Performance evaluation of powe-r demand scheduling scenarios in a SG environment. Applied Energy, 142, 164-178. https://doi.org/10.1016/j.apenergy.2014.12.060

Working Group I Contribution to the Fifth Assessment Report of the Intergovernmental Panel on Climate Change (IPCC). (2013). Climate Change 2013: The Physical Science Basis. Cambridge University Press, New York, USA.

Yu, X. B., Tan, Z. F., Chen, K. T., Ju, L. W., \& He, P. Y. (2015). Efficiency Evaluation for SG Management Based on Stochastic Frontier Model and Data Envelope Analyses Model. Mathematical Problems in Engineering. https://doi.org/10.1155/2015/142764

Zhejiang Province Economic and Information Commission (ZPEIC). (2012). White Paper of Energy and the Utilization of Zhejiang 2012. Zhejiang, China.

Zhejiang Province Economic and Information Commission (ZPEIC). (2013). White Paper of Energy and the Utilization of Zhejiang 2013. Zhejiang, China.

Zhejiang Province Economic and Information Commission (ZPEIC). (2015). White Paper of Energy and the Utilization of Zhejiang 2015. Zhejiang, China.

Zhejiang Provincial Bureau of Statistics (ZPBS). (2013). Zhejiang Statistical Yearbook 2013. Zhejiang, China.

Zhejiang Provincial Bureau of Statistics (ZPBS). (2015). Zhejiang Statistical Yearbook 2015. Zhejiang, China. 
Zhejiang Provincial Bureau of Statistics (ZPBS). (2016). Zhejiang Statistical Yearbook 2016. Zhejiang, China.

Zhejiang Provincial Development and Reform Commission (ZPDRC). (2016). The 13th Five-Yea-r Plan for Electric Power Development of Zhejiang Province. Zhejiang, China.

Zhejiang Provincial Development and Reform Commission (ZPDRC). (2012). The 12fth Five-year and Medium-long Term Plan for Renewable Energy Development of Zhejiang Province. Zhejiang, China.

Zoundi, Z. (2017). $\mathrm{CO}_{2}$ emissions, renewable energy and the Environmental Kuznets Curve, a panel co-integration approach. Renewable and Sustainable Energy Reviews, 72, 1067-1075. https://doi.org/10.1016/j.rser.2016.10.018

\section{Copyrights}

Copyright for this article is retained by the author(s), with first publication rights granted to the journal.

This is an open-access article distributed under the terms and conditions of the Creative Commons Attribution license (http://creativecommons.org/licenses/by/4.0/). 